\title{
Management Strategies of Ocular Abnormalities in Patients with Marfan Syndrome: Current Perspective
}

\author{
Hamed Esfandiari ${ }^{1,2}$, MD; Shabnam Ansari ${ }^{3}$, MD; Hossein Mohammad-Rabei ${ }^{3,4}$, MD; Marilyn B. Mets ${ }^{1,2}$, MD \\ ${ }^{1}$ Division of Ophthalmology, Ann E Robert H. Lurie Children's Hospital of Chicago, Chicago, USA \\ ${ }^{2}$ Department of Ophthalmology, Northwestern University Feinberg School of Medicine, Chicago, USA \\ ${ }^{3}$ Ophthalmic Research Center, Shahid Beheshti University of Medical Sciences, Tehran, Iran \\ ${ }^{4}$ Department of Ophthalmology, Torfeh Eye Hospital, Shahid Beheshti University of Medical Sciences, Tehran, Iran
}

ORCID:

Hamed Esfandiari: https://orcid.org/0000-0001-7301-7047

Shabnam Ansari: https://orcid.org/0000-0003-2949-3518

\section{Abstract}

Marfan syndrome is an autosomal dominant genetic connective tissue disorder that results from mutations in the fibrillin-1 gene located on chromosome band 15q15-21. Fibrillin, a glycoprotein, is widely expressed throughout the body and contributes to the elasticity and force-bearing capacity of connective tissue. In the eye, fibrillin is a key constituent of the ciliary zonules, which suspend the crystalline lens in place. The zonular defect leads to ectopia lentis, which is a hallmark of Marfan ocular abnormalities and occurs in $60 \%$ to $80 \%$ of cases. Other less common ocular features of Marfan syndrome are increased axial length, astigmatism, and flat cornea. Visual function in Marfan syndrome could be affected in several ways: ectopia lentis, refractive error, amblyopia, retinal detachment, cataract, and glaucoma. Management of a subluxated lens starts with the correction of refractive error with eyeglasses in mild cases. In more severe cases, especially when the lens bisects the pupil, complete correction of refractive error is impossible without removing the subluxated lens. The best method for visual rehabilitation after lens extraction is still debated. Aphakic Artisan lens implantation at the time of subluxated lens removal results in good visual outcomes with an acceptable safety profile. Studies with longer term follow-up and larger sample populations are needed to evaluate the safety of this procedure in patients with Marfan syndrome.

Keywords: Ectopis Lentis; Management; Marfan Syndrome; Ocular Complication; Ophthalmology

J Ophthalmic Vis Res 2019; 14 (1): 71-77

Correspondence to:

Shabnam Ansari, MD. Ophthalmic Research Center, Shahid Beheshti University of Medical Sciences, No. 23, Paidarfard St., Boostan 9 St., Pasdaran Ave., Tehran 16666, Iran.

E-mail: Sh.ansari@gmail.com

Received: 18-02-2018 Accepted: 20-10-2018

\begin{tabular}{|l|l|}
\hline \multicolumn{2}{|c|}{ Access this article online } \\
\hline Quick Response Code: & Website: \\
\hline & www.jovr.org \\
\cline { 2 - 2 } & \\
\hline
\end{tabular}

\section{INTRODUCTION}

Marfan syndrome is an autosomal dominant disease that is characterized by musculoskeletal abnormalities, cardiovascular disease, and ocular abnormalities. It is a disorder of connective tissue protein fibrillin- 1 and

This is an open access journal, and articles are distributed under the terms of the Creative Commons Attribution-NonCommercial-ShareAlike 4.0 License, which allows others to remix, tweak, and build upon the work non-commercially, as long as appropriate credit is given and the new creations are licensed under the identical terms.

For reprints contact: reprints@medknow.com

How to cite this article: Esfandiari $\mathrm{H}$, Ansari S, Mohammad-Rabei $\mathrm{H}$, Mets MB. Management strategies of ocular abnormalities in patients with Marfan syndrome: Current perspective. J Ophthalmic Vis Res 2019;14:71-7. 
transforming growth factor-beta (TGF-beta) that leads to abnormal connective tissue in many organs. ${ }^{[1]}$

It is important to diagnose patients with Marfan syndrome accurately. Ghent nosology is the well-established diagnostic criterion for Marfan syndrome. ${ }^{[2]}$ The Ghent criteria are divided into seven areas: cardiovascular system, ocular system, skeletal system, dura mater, pulmonary system, skin and integument, and family or genetic history. The major ocular criterion is ectopia lentis, and the minor ocular criteria include an abnormally flat cornea, increased axial length of the globe, and a hypoplastic iris or hypoplastic ciliary muscle causing anisocoria. Since 2010, ectopia lentis has been considered a cardinal clinical feature of Marfan syndrome, which differentiates Marfan syndrome with more sensitivity and specificity. ${ }^{[3,4]}$

Fibrillin is distributed throughout ocular tissues, so Marfan syndrome can affect different parts of the eye [Table 1].[5,6]

Almost $50 \%$ of patients are diagnosed with Marfan syndrome primarily as part of the evaluation for ophthalmic complaints. ${ }^{[7]}$ Common causes of visual abnormalities in patients with Marfan syndrome are ectopia lentis, refractive error, amblyopia, retinal detachment, cataract, and glaucoma. This present review will give a brief overview of ocular features of Marfan syndrome and discuss current management.

\begin{tabular}{|c|c|c|}
\hline \multirow[t]{4}{*}{$\begin{array}{l}\text { Anterior } \\
\text { segment }\end{array}$} & Cornea & $\begin{array}{l}\text { Flattened corneas and } \\
\text { astigmatism megalocornea }\end{array}$ \\
\hline & Angle & Glaucoma \\
\hline & Iris & $\begin{array}{l}\text { Poor dilated pupil } \\
\text { Iris coloboma } \\
\text { Iris transillumination defects } \\
\text { Iridodonesis }\end{array}$ \\
\hline & $\begin{array}{l}\text { Lens } \\
\text { abnormalities }\end{array}$ & $\begin{array}{l}\text { Ectopia lentis } \\
\text { Microspherophakia } \\
\text { Lens opacity } \\
\text { Lens coloboma }\end{array}$ \\
\hline \multirow[t]{2}{*}{$\begin{array}{l}\text { Posterior } \\
\text { segment }\end{array}$} & Vitreous & $\begin{array}{l}\text { Liquefaction } \\
\text { Abnormal vitreous } \\
\text { attachments along the lattice } \\
\text { degenerations }\end{array}$ \\
\hline & Retina & $\begin{array}{l}\text { Retinal degeneration } \\
\text { Retinal tears } \\
\text { Retinal detachment }\end{array}$ \\
\hline Choroid & & Thin choroid \\
\hline Sclera & & Thin sclera (1) \\
\hline Globe & & $\begin{array}{l}\text { Long axial length } \\
\text { strabismus }\end{array}$ \\
\hline
\end{tabular}

1.Turaga K, Senthil S, Jalali S. Recurrent spontaneous scleral rupture in Marfan's syndrome. BMJ case reports. 2016;2016. Epub 2016/05/21

\section{Ectopia Lentis}

Ectopia lentis or lens subluxation is the predominant ocular complication of Marfan syndrome. ${ }^{[8,9]}$ The incidence of ectopia lentis in Marfan syndrome varies from $30 \%$ to $72 \%$ in different studies and tends to occur in the fourth and fifth decade of life..$^{[10-15]}$ Zonules suspend the crystalline lens behind the iris and they are made of fibrillin. Fibrillin abnormalities in Marfan syndrome lead to zonular weakness and subluxation of the lens. Subluxation is usually toward superior and temporal directions, although dislocation into the vitreous or anterior chamber may also occur. ${ }^{[16]}$

This abnormality may present with symptoms like blurred vision, fluctuating vision, and monocular diplopia. Ocular examination may show lens subluxation, dislocation, iridodonesis, and irregular astigmatism..$^{[5,17]}$

Eyeglasses are the first step to correct blurred vision caused by subluxated lenses. ${ }^{[5]}$ Prescribing glasses in Marfan patients with a subluxated lens is challenging. ${ }^{[18]}$ In mild cases, correcting myopic astigmatism is all that patients need. If the subluxated lens splits the pupil, correcting the aphakic part leads to a better outcome as images are less distorted by lenticular astigmatism. Ophthalmologists should decide whether the aphakic or phakic pupil must be corrected. In the case of mild subluxation, the patient sees through the crystalline lens and lenticular astigmatism should be corrected. With significant lens subluxation, clear view through the lens is impossible and aphakic eyeglasses should be prescribed. ${ }^{[19]}$

Depending on the patient's age, preference, job, and other conditions, contact lenses can be used as an alternative.

In the past, because of the high rate of intra- and postoperative complications and poor visual outcomes in Marfan syndrome, surgery was not a popular option. ${ }^{[20]}$ Nowadays with the advance in microsurgical instruments and operation techniques, interest has grown in surgery to improve visual function.

Lens extraction is the main type of treatment for anterior lens dislocation.

The indications for surgery in lens dislocation are inability to achieve good corrected visual acuity, risk of amblyopia in children, posterior dislocation of the lens into the vitreous cavity, anterior dislocation of the lens with or without secondary glaucoma, impending to complete lens dislocation, lens induced glaucoma or uveitis, and cataract.

Subluxated lens extraction in these patients is challenging. The zonular weakness and lens instability is frequently complicated by the loss of the capsular bag, vitreous disturbance, and endothelial cell damage.

Forty eyes of patients with Marfan syndrome who underwent pars plana vitreolensectomy for subluxated lenses were evaluated. Patients in this series had mean 
improvement of 2.8 lines Snellen acuity and no visual acuity reduction was reported. The surgery had an acceptable complication rate and the postoperative incidence of retinal detachment was $6 \% .{ }^{[21]}$

Within the bag lensectomy combined with a limited anterior vitrectomy is a safe procedure in children with lens subluxation. Anteby et al followed 22 cases of Marfan syndrome with a subluxated lens who underwent within the bag lensectomy for $6 \pm 4.6$ years and demonstrated stable visual acuity with minor fluctuations as well as normal intraocular pressure in all cases. ${ }^{[20]}$ Only one case developed retinal detachment four years after the surgery, which emphasizes the importance of long-term follow-up in these cases.

Although lens extraction is considered a safe and effective method to remove subluxated or dislocated lenses, retinal detachment is a possible complication in Marfan syndrome. ${ }^{[22-25]}$

Visual rehabilitation after lens extraction is an unresolved dilemma. Aphakic glasses are the safest method to correct aphakia and provide a consistent visual outcome in patients. It is especially important in pediatric patients, in whom follow-up for artificial intraocular lenses is limited. ${ }^{[24,26]}$

Lens extraction combined with artificial intraocular lens replacement is another choice for surgery for Marfan syndrome. ${ }^{[27]}$ Options for an intraocular lens include an anterior chamber intraocular lens (ACIOL), a posterior chamber intraocular lens (PCIOL) fixed to the sclera and/or to the iris, and scleral fixated capsular tension rings.

Not long ago, flexible open-loop ACIOL implantation was the most commonly used method for aphakic correction. Pars plana lensectomy with primary ACIOL implantation in both children and adults with Marfan syndrome demonstrated good postoperative corrected visual acuity and no serious complications in short-term follow-up. ${ }^{[28,29]}$ However, there are concerns regarding this practice in Marfan syndrome. The anterior chamber is excessively deep in most Marfan cases, which prevents appropriate fitting of the IOL and leads to exaggerated IOL movement. A loose fit causes pigment release, glaucoma, corneal decompensation, and inflammation.

Considering these complications, PCIOLs seem to be a better option as they are not positioned in the anterior chamber and their size is bigger than ACIOLs. PCIOL implantation in these cases is technically demanding and needs more time. Scleral fixation of PCIOLs in children without adequate capsular support can be visually rewarding in selected cases, but there is a high rate of complications during long-term follow-up. ${ }^{[30]}$

Sulcus fixation of an IOL in eyes without capsular support is an option to correct aphakia in children. ${ }^{[31]}$ In their study, Zetterstrom et al implanted the IOL into the sulcus and sutured the haptics of the IOL to the scleral bed. They followed their cases for nine to 33 months and no opacification of the visual axis, secondary glaucoma, or retinal complication were reported during follow-up.

Aspiotis et al performed lens extraction and Artisan (iris claw ACIOL) IOL implantation in two children and three adults with lens subluxation due to Marfan syndrome. ${ }^{[32,33]}$ In their report, best-corrected visual acuity improved 4 Snellen lines and endothelial cell counts remained constant during six months of follow-up. Following this study, Samina et al presented two patients with Marfan syndrome who underwent lens extraction and Artisan implantation that were followed up for 12 years. This long-term follow-up showed good visual outcomes and no serious IOL-related complications. ${ }^{[34]}$ Endothelial cell counts were within the expected range for their age at the final follow-up visit. Cevik et al reported outcomes of Artisan iris-claw lens implantation in children with non-traumatic ectopia lentis. They concluded that Artisan provides good results in terms of improving uncorrected and corrected vision, but involves a high incidence of postoperative complications, especially lens dislocation and retinal detachment. ${ }^{[35]}$

In another cases series, Rabie et al evaluated the outcome of lens extraction and Artisan implantation in 12 eyes of nine patients with Marfan syndrome. Only one case of retinal detachment two months after the surgery and one case of IOL subluxation were reported in this series during 44.5 months of follow-up. ${ }^{[36]}$

The main concern regarding Artisan fixation is endothelial cell loss. Because of their retrospective nature, none of the previous studies evaluated the endothelial cell counts before and after IOL implantation. Other studies compared the cell counts with age matched populations and reported no significant difference. ${ }^{[32,34]}$

In a randomized clinical trial, endothelial cell loss in an iris fixated IOL group was $19.3 \%$ at a one-year follow-up, which was comparable to the loss in the sclera fixation group. ${ }^{[37]}$

In an attempt to save the cornea from possible IOL induced damages, retropupillary iris-claw IOL fixation is also used to correct aphakia in these cases. ${ }^{[38]}$

Leubke et al compared the long-term follow-up of scleral IOL fixation in patients with Marfan syndrome with that in non-Marfan patients. They reported significantly more IOL dislocation in patients with Marfan patients compared to non-Marfan patients. ${ }^{[39]}$

Few studies in the literature compared different types of IOL implantation in Marfan syndrome. ${ }^{[37,40]}$ In a randomized clinical trial, Zheng et al compared clinical outcomes of iris fixated ACIOL and scleral fixated PCIOL in 71 eyes of 49 patients with Marfan syndrome and lens subluxation. While endothelial cell loss was comparable between the two groups, complications were significantly higher in the sclera fixation group and almost $50 \%$ of cases developed IOL decentration. ${ }^{[37]}$

Another option to stabilize the capsular bag is to use a capsular tension ring (CTR). Nonetheless, a CTR cannot 
correct decentration and since the zonular weakness in Marfan syndrome is progressive, both IOLs and CTRs are subject to further decentration or even dislocation. ${ }^{[41]}$

To overcome this obstacle, Bahar et al used a Cionni ring and sutured it to the sclera in 12 eyes of nine patients with Marfan syndrome. IOL centration was excellent during follow-up but three patients developed posterior capsule opacification. ${ }^{[18,42,43]}$

IOL power calculation is also an important issue in patients with Marfan syndrome. They usually have a longer axial length and a staphylomatous area in the posterior pole that can lead to axial length miscalculation with ultrasound biometry. If the ultrasound waves hit the staphyloma, the calculated power of IOL results in underestimation and hyperopia after surgery. ${ }^{[40,44]}$

\section{Refractive Error}

Most of the patients with Marfan syndrome have myopia due to long axial length. The prevalence of myopia in Marfan syndrome (34\%-44\%) is higher than in the general population. ${ }^{[5,9-11]}$ In one report, more than $50 \%$ of patients with Marfan syndrome have myopia of $3.00 \mathrm{D}$ or more. ${ }^{[45]}$ They may also suffer from lenticular astigmatism due to lens subluxation. Kinori et al showed increased corneal astigmatism in addition to lenticular astigmatism. ${ }^{[46]}$

Refractive error can be corrected with glasses or contact lenses (special flat contacts may be required for proper correction).

Corneal refractive surgery (laser keratotomy) is not recommended for most patients with Marfan syndrome, as the cornea is markedly flat in these cases.

Mild cases of myopia can be corrected with laser surgery in people with Marfan syndrome if they do not have lens dislocation. In the presence of lens subluxation, laser ablation is not recommended because it may make the dislocation worse in the case of LASIK surgery, and also interfere with detailed IOL calculation for future IOL implantation.

\section{Amblyopia}

Children with Marfan syndrome are at risk of amblyopia. Ocular abnormalities such as myopia, astigmatism, anisometropia, ectopia lentis, and retinal pathologies may result in amblyopia.

Romano et al evaluated the visual outcome of conservative (non-surgical) therapy in patients with hereditary ectopia lentis. Almost half of the cases developed significant permanent functional amblyopia (visual acuity of 20/50 to 20/200) in spite of good conservative management. The worst amblyopia occurred when the lens was still covering the visual axis and the lens edge was $1.3 \mathrm{~mm}$ from the center of the pupil (range of 0.3 to $2.3 \mathrm{~mm}$ ). Based on this study, early surgical intervention in children with lens subluxation who are nonresponsive to conservative management should be considered. ${ }^{[47]}$

\section{Retinal Disease}

Posterior segment pathology is present in $18 \%$ of eyes in Marfan syndrome and the incidence is even higher (70\%) in patients with a subluxed lens. ${ }^{[48]}$ The incidence of retinal detachment in Marfan syndrome ranges from $5 \%$ to $25.6 \% .^{[15,24,49,50]}$

The peripheral retinal changes include myopic degeneration, lattice degeneration, atrophic holes, chorioretinal pigment proliferation, peripheral vitreous traction syndromes, and retinal breaks.

Predisposing factors for retinal breaks in Marfan syndrome include ectopia lentis, long axial length, early vitreous liquefaction, posterior vitreous detachment without any dehiscence at the vitreoretinal interface, and abnormal peripheral vitreoretinal adhesions. Extensive vitreous liquefaction in central and peripheral areas is a common finding in patients with Marfan syndrome. In addition, vitreous attachment along the edges of peripheral retinal abnormalities such as lattice degeneration is common finding in these patients. Risk factors for retinal detachment in Marfan syndrome include younger age, ectopia lentis, and a history of lensectomy and aphakia. ${ }^{[5,25,49,51,52]}$ Chandra et al reported that women with Marfan syndrome seem to have developed retinal detachment earlier than men with Marfan syndrome. ${ }^{[15]}$

Because of the risk of retinal detachment, people with Marfan syndrome should have a complete ophthalmic exam routinely once a year and any time they have any ophthalmic complaint. In cases of limited cooperation, such as young age and ocular abnormalities such as miotic pupil, an ophthalmologist can use widefield retinal imaging to complete the retinal exam. ${ }^{[48]}$

Treatment in most cases is surgical intervention and it should be performed as soon as possible. Retinal detachment surgery in Marfan syndrome is challenging because of ocular abnormalities such as a thin sclera, miotic pupils, and multiple breaks. ${ }^{[17]}$ In the past, surgeries for retinal detachment in Marfan syndrome had less favorable outcomes than surgeries for retinal detachment in the normal population. Nowadays, with modern surgical techniques and instrumentation, the outcome of retinal surgery is comparable between patients with Marfan syndrome and the normal population. Currently available vitreoretinal surgical techniques result in successful reattachment of the retina in approximately $86 \%$ of eyes. ${ }^{[49,50]}$ Failure of surgery in Marfan syndrome is due to proliferative retinopathy and poor visualization of the retinal periphery. ${ }^{[25,51,53]}$

Two surgical procedures for retinal detachment repair are scleral buckling and vitreous surgery. The choice of surgery depends on lens status and location, fundus visibility and retinal tear properties. Patients with normal or subluxated lens without any interference with funduscopy or the retinal breaks are at or anterior to the equator, should be undergone scleral buckling. 
Vitreoretinal surgery is recommended for patients with history of failed scleral buckling, posterior lens dislocation, subluxated or cataractous lens that interference with funduscopy and giant retinal tears. ${ }^{[54,55]}$

Prognosis depends on the nature of the retinal tear, the location and extent of the detachment, the presence of PVR (proliferative vitreoretinopathy), the time interval between symptom onset and surgery, and phakic or aphakic condition.

According to recent studies, the results of surgery are comparable with those in patients without Marfan syndrome, and successful retinal reattachment is achieved in $86 \%{ }^{[54]}$ to $100 \%{ }^{[55]}$ of cases. Poorer visual outcome is likely when there is concomitant lens dislocation or a history of intraocular surgery. ${ }^{[56]}$

Retinal detachment in patients with Marfan syndrome tends to occur bilaterally $(30 \%-42 \%$ of cases). It is important to carefully examine the fellow eye and do preventive barrier laser treatment if necessary. ${ }^{[51-53]}$

\section{Cataract}

Although the prevalence of cataract does not seem to be higher in Marfan syndrome, it tends to occur at a younger age. Posterior subcapsular cataracts and localized globular lens opacities are common types of cataracts in Marfan syndrome. ${ }^{[12]}$

Marfan syndrome is associated with significant zonular weakness. As zonular weakness renders the eye susceptible to surgical complications, surgery should be performed by an experienced surgeon in a well equipped operation room. Surgeons may need to use a modified CTR (capsular tension ring) during cataract surgery in both adult and pediatric eyes in Marfan syndrome due to severe zonular insufficiency. ${ }^{[16,57,58]}$ Rosenthal et al used viscoadaptive ophthalmic viscosurgical devices to distend and stabilize the capsular bag with or without early insertion of a CTR during lens extraction and IOL implantation. This approach may be used as an alternative technique. ${ }^{[59]}$

Intra operation complications include vitreous loss, rupture of the residual zonules, and extension of the capsulotomy. Post-operation complications include vitreous incarceration in the wound, iris prolapse, corneal edema, postoperative hyphema, and persistent postoperative iritis. ${ }^{[10]}$

Femtosecond laser-assisted cataract surgery is another approach for cataract surgery in patients with Marfan syndrome. Benefits of this technique in these patients include a circular, well centered capsulotomy, slow motion phacoemulsification, minimal further zonular damage, and treatment of corneal astigmatism with relaxing incisions. ${ }^{[60,61]}$

\section{Glaucoma}

About one-third of patients with Marfan syndrome will develop glaucoma some time in their life. ${ }^{[17]}$ Usually, in these cases, glaucoma is diagnosed at a younger age than in the general population.

The most common type of glaucoma in Marfan syndrome is primary open angle glaucoma. While primary angle closure glaucoma has not been reported in this condition, a pupillary block mechanism can rarely happen due to anterior dislocation of the lens. ${ }^{[5,16]}$ Although not as common as in hemochromatosis, anterior lens dislocation may happen spontaneously or secondary to trauma. ${ }^{[16,45]}$ In this situation, lensectomy is a definite treatment.

The possible mechanism for open angle glaucoma is the abnormal insertion of the ciliary musculature into the trabecular meshwork and displacement of Schlemm's

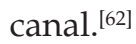

Secondary open angle glaucoma may occur due to retinal detachment, vitreoretinal or lens extraction surgeries, iritis, or pigment dispersion due to excessive movement of a PCIOL. ${ }^{[62]}$

Kale et al reported a patient with neonatal Marfan syndrome with a rare ocular manifestation of bilateral angle closure glaucoma. ${ }^{[63]}$

Management of glaucoma starts with antiglaucoma medications. If the patients use a systemic beta-blocker for cardiovascular abnormalities, a topical beta-blocker has minimal effect on lowering the intraocular pressure.

The choice of glaucoma surgery in patients with Marfan syndrome depends on the lens position. If the lens is normal, minimally invasive glaucoma surgeries or non-penetrating deep sclerotomy are preferred first line interventions. These eyes are more susceptible to hypotony related complications of incisional surgeries, and there is a risk of further lens subluxation in the postoperative fluctuating anterior chamber. ${ }^{[64]}$

\section{SUMMARY}

Ophthalmologists play a substantial role in detecting Marfan syndrome. The diagnosis and management of the associated eye conditions are challenging. Patients should be evaluated by an ophthalmologist for refraction, intraocular pressure, lens status, peripheral retina status, and changes in the optic nerve.

In the case of lens subluxation, the first line of management is correcting the refractive error with eyeglasses. If the lens is bisecting the pupil, eyeglasses alone are unlikely to correct visual function, and the removal of the crystalline lens is necessary. In most cases, an aphakic Artisan IOL is a safe and effective means for visual rehabilitation. After the surgery, patients should be routinely followed for IOL centration and changes to the retinal periphery. Patients should also be advised to seek instant ophthalmological consultation if they see flashes and floaters, or experience any partial or complete loss of visual acuity. Timely intervention for retinal detachment can preserve patients' visual function. 


\section{Financial Support and Sponsorship}

Nil.

\section{Conflicts of Interest}

There are no conflicts of interest.

\section{REFERENCES}

1. Boileau C, Jondeau G, Mizuguchi T, Matsumoto N. Molecular genetics of Marfan syndrome. Curr Opin Cardiol 2005;20:194-200.

2. De Paepe A, Devereux RB, Dietz HC, Hennekam RC, Pyeritz RE. Revised diagnostic criteria for the Marfan syndrome. Am J Med Genet 1996;62:417-426.

3. Loeys BL, Dietz HC, Braverman AC, Callewaert BL, De Backer J, Devereux RB, et al. The revised Ghent nosology for the Marfan syndrome. J Med Genet 2010;47:476-485.

4. Penpattharakul W, Pithukpakorn M. Revised Ghent criteria is comparable to original diagnostic criteria for Marfan syndrome with increased ability to clinically diagnose related disorders. J Med Assoc Thai 2016;99:34-39.

5. Nemet AY, Assia EI, Apple DJ, Barequet IS. Current concepts of ocular manifestations in Marfan syndrome. Surv Ophthalmol 2006;51:561-575.

6. Turaga K, Senthil S, Jalali S. Recurrent spontaneous scleral rupture in Marfan's syndrome. BMJ Case Rep 2016;2016. doi: 10.1136/ bcr-2016-214764.

7. Strider D, Moore T, Guarini J, Fallin B, Ivey J, Kron I. Marfan's Syndrome: A Family Affair; 1997. 91-98 p.

8. Mema V, Qafa N. Ocular complications of marfan syndrome. Report of two cases. Hippokratia 2010;14:45-47.

9. Gehle P, Goergen B, Pilger D, Ruokonen P, Robinson PN, Salchow DJ. Biometric and structural ocular manifestations of Marfan syndrome. PloS One 2017;12:e0183370.

10. Lim AY, Song JS, Kim EK, Jang SY, Chung TY, Choi SH, et al. Clinical characteristics of Marfan syndrome in Korea. Korean Circ J 2016;46:841-845.

11. Drolsum L, Rand-Hendriksen S, Paus B, Geiran OR, Semb SO. Ocular findings in 87 adults with Ghent-1 verified Marfan syndrome. Acta Ophthalmol 2015;93:46-53.

12. Pyeritz RE. The Marfan syndrome. Ann Rev Med 2000;51:481-510.

13. Wakita M, Ryu E, Nakayasu K, Kashima K, Fujiki K, Kato K, et al. [Statistical analysis of Marfan's syndrome]. Nippon Ganka Gakkai Zasshi 1989;93:682-690.

14. Fuchs J, Rosenberg T. Congenital ectopia lentis. A Danish national survey. Acta Ophthalmol Scand 1998;76:20-26.

15. Chandra A, Ekwalla V, Child A, Charteris D. Prevalence of ectopia lentis and retinal detachment in Marfan syndrome. Acta Ophthalmol 2014;92:e82-e83.

16. Cross HE, Jensen AD. Ocular manifestations in the Marfan syndrome and homocystinuria. Am J Ophthalmol 1973;75:405-420.

17. Nahum Y, Spierer A. Ocular features of Marfan syndrome: Diagnosis and management. Isr Med Assoc J 2008;10:179-181.

18. Konradsen T, Kugelberg M, Zetterstrom C. Visual outcomes and complications in surgery for ectopia lentis in children. J Cataract Refract Surg 2007;33:819-824.

19. Sah RP, Paudel N, Shrestha JB. Marfan's syndrome: A refractive challenge for optometrists. Clin Exp Optom 2013;96:581-583.

20. Anteby I, Isaac M, BenEzra D. Hereditary subluxated lenses: Visual performances and long-term follow-up after surgery. Ophthalmology 2003;110:1344-1348.

21. Hubbard AD, Charteris DG, Cooling RJ. Vitreolensectomy in Marfan's syndrome. Eye (Lond) 1998;12:412-416.

22. Manning S, Lanigan B, O'Keefe M. Outcomes after lensectomy for children with Marfan syndrome. J AAPOS 2016;20:247-251.

23. Wu-Chen WY, Letson RD, Summers CG. Functional and structural outcomes following lensectomy for ectopia lentis. J AAPOS 2005;9:353-357.

24. Miraldi Utz V, Coussa RG, Traboulsi EI. Surgical management of lens subluxation in Marfan syndrome. I AAPOS 2014;18:140-146.

25. Halpert M, BenEzra D. Surgery of the hereditary subluxated lens in children. Ophthalmology 1996;103:681-686.

26. Neely DE, Plager DA. Management of ectopia lentis in children. Ophthalmol Clin N Am 2001;14:493-499.

27. Vadala P, Capozzi P, Fortunato M, DeVirgiliis E, Vadala F. Intraocular lens implantation in Marfan's syndrome. J Pediatr Ophthalmol Strabismus 2000;37:206-208.

28. Morrison D, Sternberg P, Donahue S. Anterior chamber intraocular lens (ACIOL) placement after pars plana lensectomy in pediatric Marfan syndrome. J AAPOS 2005;9:240-242.

29. Biro Z, Szabo I, Pamer Z. Combined cataract surgery on a Marfan-syndrome patient (case report). Oftalmologia (Bucharest, Romania: 1990) 2014;58:30-33.

30. Asadi R, Kheirkhah A. Long-term results of scleral fixation of posterior chamber intraocular lenses in children. Ophthalmology 2008;115:67-72.

31. Zetterstrom C, Lundvall A, Weeber H Jr, Jeeves M. Sulcus fixation without capsular support in children. J Cataract Refract Surg 1999;25:776-781.

32. Aspiotis M, Asproudis I, Stefaniotou M, Gorezis S, Psilas K Artisan aphakic intraocular lens implantation in cases of subluxated crystalline lenses due to Marfan syndrome. I Refract Surg 2006;22:99-101.

33. Lifshitz T, Levy J, Klemperer I. Artisan aphakic intraocular lens in children with subluxated crystalline lenses. J Cataract Refract Surg 2004;30:1977-1981.

34. Sminia ML, Odenthal MT, Prick LJ, Cobben JM, Mourits MP, Volker-Dieben HJ. Long-term follow-up after bilateral Artisan aphakia intraocular lens implantation in two children with Marfan syndrome. J AAPOS 2012;16:92-94.

35. Cevik SG, Cevik MO, Ozmen AT. Iris-claw intraocular lens implantation in children with ectopia lentis. Arq Bras Oftalmol 2017;80:114-117.

36. Rabie HM, Malekifar P, Javadi MA, Roshandel D, Esfandiari H. Visual outcomes after lensectomy and iris claw artisan intraocular lens implantation in patients with Marfan syndrome. Int Ophthalmol 2017;37:1025-1030.

37. Zheng D, Wan P, Liang J, Song T, Liu Y. Comparison of clinical outcomes between iris-fixated anterior chamber intraocular lenses and scleral-fixated posterior chamber intraocular lenses in Marfan syndrome with lens subluxation. Clin Exp Ophthalmol 2012;40:268-274.

38. Faria MY, Ferreira N, Neto E. Retropupillary iris-claw intraocular lens in ectopia lentis in Marfan syndrome. Int Med Case Rep J 2016;9:149-153.

39. Luebke J, Reinhard T, Agostini H, Boehringer D, Eberwein P. Long-term follow-up after scleral lens fixation in patients with Marfan syndrome. BMC Ophthalmol 2017;17:235.

40. Siganos DS, Siganos CS, Popescu CN, Margaritis VN. Clear lens extraction and intraocular lens implantation in Marfan's syndrome. J Cataract Refract Surg 2000;26:781-784.

41. Dietlein TS, Jacobi PC, Konen W, Krieglstein GK. Complications of endocapsular tension ring implantation in a child with Marfan's syndrome. J Cataract Refract Surg 2000;26:937-940.

42. Bahar I, Kaiserman I, Rootman D. Cionni endocapsular ring implantation in Marfan's Syndrome. Br J Ophthalmol 2007;91:1477-1480.

43. Kohnen T, Baumeister M, Buhren J. Scheimpflug imaging of bilateral foldable in-the-bag intraocular lens implantation assisted 
by a scleral-sutured capsular tension ring in Marfan's syndrome. J Cataract Refract Surg 2003;29:598-602.

44. Jimenez-Alfaro I, Miguelez S, Bueno JL, Puy P. Clear lens extraction and implantation of negative-power posterior chamber intraocular lenses to correct extreme myopia. J Cataract Refract Surg 1998;24:1310-1316.

45. Maumenee IH. The eye in the Marfan syndrome. Trans Am Ophthalmol Soc 1981;79:684-733.

46. Kinori M, Wehrli S, Kassem IS, Azar NF, Maumenee IH, Mets MB. Biometry characteristics in adults and children with Marfan syndrome: From the Marfan Eye Consortium of Chicago. Am J Ophthalmol 2017;177:144-149.

47. Romano PE, Kerr NC, Hope GM. Bilateral ametropic functional amblyopia in genetic ectopia lentis: Its relation to the amount of subluxation, an indicator for early surgical management. Binocul Vis Strabismus Q 2002;17:235-241.

48. Rahmani S, Lyon AT, Fawzi AA, Maumenee IH, Mets MB. Retinal disease in Marfan syndrome: From the Marfan Eye Consortium of Chicago. Ophthalmic Surg Lasers Imaging Retina 2015;46:936-941.

49. Dotrelova D, Karel I, Clupkova E. Retinal detachment in Marfan's syndrome. Characteristics and surgical results. Retina (Philadelphia, Pa) 1997;17:390-396.

50. Remulla JF, Tolentino FI. Retinal detachment in Marfan's syndrome. Int Ophthalmol Clin 2001;41:235-240.

51. Abboud EB. Retinal detachment surgery in Marfan's syndrome. Retina (Philadelphia, Pa) 1998;18:405-409.

52. Freeman HM. Fellow eyes of giant retinal breaks. Trans Am Ophthalmol Soc 1978;76:343-382.

53. Dotrelova D. Bilateral retinal detachment in Marfan's syndrome. Eur J Ophthalmol 1998;8:102-105.

54. Sharma T, Gopal L, Shanmugam MP, Bhende PS, Agrawal R, Shetty NS, et al. Retinal detachment in Marfan syndrome: Clinical characteristics and surgical outcome. Retina (Philadelphia, $\mathrm{Pa}$ ) 2002;22:423-428

55. Lee SY, Ang CL. Results of retinal detachment surgery in Marfan syndrome in asians. Retina (Philadelphia, Pa) 2003;23:24-29.

56. Loewenstein A, Barequet IS, De Juan E Jr, Maumenee IH. Retinal detachment in Marfan syndrome. Retina (Philadelphia, $\mathrm{Pa}$ ) 2000;20:358-363.

57. Li B, Wang Y, Malvankar-Mehta MS, Hutnik CM. Surgical indications, outcomes, and complications with the use of a modified capsular tension ring during cataract surgery. J Cataract Refract Surg 2016;42:1642-1648.

58. Malyugin B. The results of cataract surgery in patients with Marfan's syndrome with the new CTR. Zdrav Vestn 2012; 81:I61-I66.

59. Rosenthal KJ, Venkateswaran N. Capsular bag stabilization during lens extraction and intraocular lens implantation in cases of Marfan syndrome with ectopia lentis using ultra-high-viscosity ophthalmic viscosurgical devices. J Cataract Refract Surg 2016;42:1397-1401.

60. Schultz T, Ezeanosike E, Dick HB. Femtosecond laser-assisted cataract surgery in pediatric Marfan syndrome. J Refract Surg 2013;29:650-652.

61. Alexandr Stepanov PR. Femtosecond laser-assisted cataract surgery in Marfan syndrome. J Clin Exp Ophthalmol 2015;06. doi: 10.4172/2155-9570.1000426.

62. Burian HM, Allen L. Histologic study of the chamber angel of patients with Marfan's syndrome. A discussion of the cases of Theobald, Reeh and Lehman, and Sadi de Buen and Velazquez. Arch Ophthalmol 1961;65:323-333.

63. Kale Y, Isik DU, Celik U, Hekimoglu E, Celik IH, Bas AY, et al. Neonatal Marfan syndrome with angle-closure glaucoma, tricuspid and mitral insufficiency. Genet Couns 2015;26:95-98.

64. Krupin T. Marfan syndrome, lens subluxation, and open-angle glaucoma. J Glaucoma 1999;8:396-399. 